\title{
A Study of Interactivity in Human Computer Interaction
}

\author{
K P Tripathi \\ Assistant Professor (MCA Programme) \\ Bharati Vidyapeeth Deemed University \\ Institute of Management \\ Kolhapur, India
}

\begin{abstract}
Human-computer interaction (HCI) is the study of how people design, implement, and use interactive computer systems and how computers affect individuals, organizations and society. This encompasses not only ease of use but also new interaction techniques for supporting user tasks, providing better access to information, and creating more powerful forms of communication. It involves input and output devices and the interaction techniques that use them; how information is presented and requested; how the computer's actions are controlled and monitored; all forms of help, documentation, and training; the tools used to design, build, test, and evaluate user interfaces; and the processes that developers follow when creating Interfaces. This paper is an attempt to highlights the study of interaction between people (users) and computers.
\end{abstract}

\section{Keywords}

Human Computer Interaction, Human Information Processing, Decision Making

\section{INTRODUCTION}

Human-computer interaction (HCI) is the study of interaction between people (users) and computers. It is often regarded as the intersection of computer science, behavioral sciences, design and several other fields of study. Interaction between users and computers occurs at the user interface, which includes both software and hardware; for example, characters or objects displayed by software on a personal computer's monitor, input received from users via hardware peripherals such as keyboards and mice, and other user interactions with large-scale computerized systems such as aircraft and power plants. The Association for Computing Machinery defines human-computer interaction as "a discipline concerned with the design, evaluation and implementation of interactive computing systems for human use and with the study of major phenomena surrounding them. Because human-computer interaction studies a human and a machine in conjunction, it draws from supporting knowledge on both the machine and the human side. On the machine side, techniques in computer graphics, operating systems, programming languages, and development environments are relevant. On the human side, communication theory, graphic and industrial design disciplines, linguistics, social sciences, cognitive psychology, and human factors are relevant. Engineering and design methods are also relevant. [1] Due to the multidisciplinary nature of HCI, people with different backgrounds contribute to its success. HCI is also sometimes referred to as man-machine interaction (MMI) or computer-human interaction (CHI).

\section{HUMAN COMPUTER INTERACTION}

The human-computer interaction can be described as the point of communication between the human user and the computer. The flow of information between the human and computer is defined as the loop of interaction [2] [3]. The loop of interaction has several aspects to it including:

1. Task Environment: The conditions and goals set upon the user.

2. Machine Environment: The environment that the computer is connected to.

3. Areas of the Interface: Non-overlapping areas involve processes of the human and computer not pertaining to their interaction. Meanwhile, the overlapping areas only concern themselves with the processes pertaining to their interaction.

4. Input Flow: The flow of information that begins in the task environment, when the user has some task that requires using their computer.

5. Output: The flow of information that originates in the machine environment.

6. Feedback: Loops through the interface that evaluate, moderate, and confirm processes as they pass from the human through the interface to the computer and back.

\section{HUMAN COMPUTER INTERACTION GOALS}

The basic goal of HCI is to improve the interactions between users and computers by making computers more usable and receptive to the user's needs. Specifically, HCI is concerned with:

1. Methodologies and processes for designing interfaces (i.e., given a task and a class of users, design the best possible interface within given constraints, optimizing for a desired property such as learning ability or efficiency of use).

2. Methods for implementing interfaces (e.g. software toolkits and libraries; efficient algorithms)

3. Techniques for evaluating and comparing interfaces

4. Developing new interfaces and interaction techniques

5. Developing descriptive and predictive models and theories of interaction

\section{NEWELL AND SIMON MODEL FOR HUMAN INFORMATION PROCESSING}

Newell and Simon [6] formulated a methodology for human information processing. According to this model, a human being interacts with the external environment, gets information, and processes them. The initial interaction between the human being 
and the environment is triggered by stimuli. The sensory organs (receptors) accept the environment and pass it on to the brain (processor). Decisions made by the brain are conveyed to the environment by various organs of the human body (effectors) in the form of speech, physical activity, written messages etc.

A well-known model on the human decision-making process was proposed by H.A. Simon. Simon's decision-making model $[1,6]$ consists of three major stages:

Stage 1: Problem identification and data collection stage (also called intelligence phase).

Stage 2: Identification and planning of alternate solutions (also called design phase).

Stage 3: Selection of a solution from multiple alternatives, implementing and monitoring (also called choice phase).

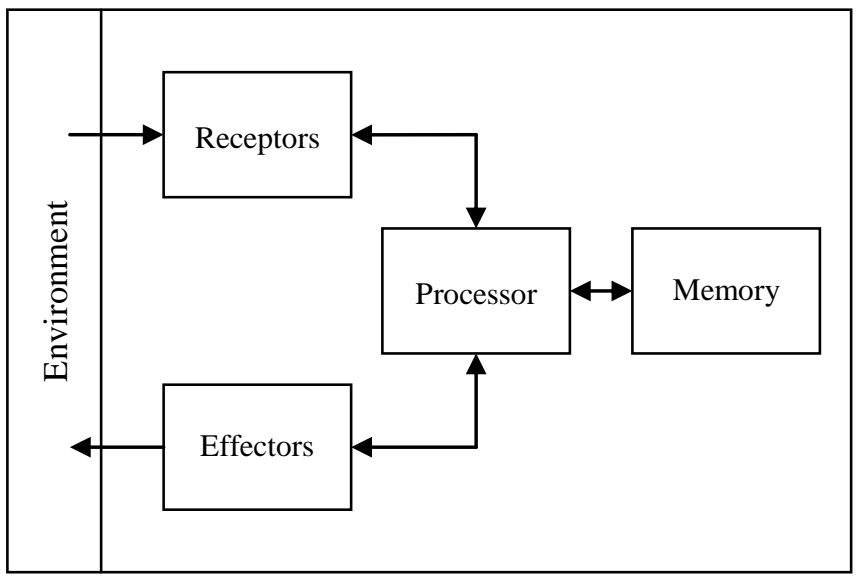

Figure 1: Newell and Simon Model of Human Problem Solving

The interface between humans and the system plays a key role in information systems. The attitude and approach of the users towards systems especially computerized systems plays in important role in the successful implementation. From the viewpoint of the user, the interface is the only important component in the information system as the user is unaware of other components with which the user has no interaction. [1]

\section{WHY DO HUMANS USE COMPUTING SYSTEMS?}

For millions of years, humans have used tools to ease the tasks they need to perform in order to survive. From historical tools such as chiseled-rock spear points to tools of the 21 st century, humans have used their innovative talents and their enriched understanding of science to create technologies and tools to support their needs. Computing systems are the latest and arguably most complex tools that humans have ever created. Their use continues to evolve and grow as their speed and capability increase.

From their earliest days, computers were used for scientific, engineering, and cryptographic computations. Early human users of computers both wrote and read the bits that computers understood. With the advent of programming languages and translators such as assemblers and compilers, humans used characters (numbers, letters, and punctuation) and words to write instructions in ways that humans understood, and which translators turned into computer readable commands. Conversely, computers converted the bits that comprised the results of computations into numbers, words, and sentences that humans understood. Humans viewed the content created by computers as reflecting that computers could think which greatly expanded the potential roles computers could play. Computers could not just compute, but could also produce sentences that people could understand. Understanding what a computer is doing in human terms rather than in computer terms was an early step in human-computer interaction. As humans observed what computers could do, they adapted the computer's capabilities to satisfy their needs and desires. Today humans' use computers to communicate, interact, and share in diverse ways:

1. To write and talk to each other

2. To exchange artifacts of personal interest such as photos, music, and videos

3. To exchange artifacts used in the workplace such as text files, drawings, and visualizations

Ideas about what computers could do for humans grew as single stand-alone computers that performed only one set of calculations using data on external media such as tapes evolved into our multifunctional 21 st century systems. More ideas came as networks of computing systems were built to transmit bits almost instantaneously around the world for other computers and software and people to use. In a seemingly never-ending cycle, new computer-enabled capabilities, devices, and environments are envisioned, developed, and deployed for use by ever larger, more diverse, and more demanding populations. These human activities have greatly expanded computer usage. [5]

Humans use computers to meet their needs and desires as long as they can easily do so. A user will not invest in learning to use a computer when such learning is disproportionate to meeting those needs and desires. User communities assess ease-of-use differently, and the great variability in human needs and capabilities means that ease-of-use has many aspects. For example, astrophysicists will invest extraordinary effort to use fast new (and difficult-to-use) computing systems to conduct their research because they have no viable alternative. Each science and engineering community has its own assumptions, data, information, vocabulary, computing needs, and ways to communicate, interact, and share. Each community has developed its own computing system capabilities. Building easily traversed bridges among such systems and across nations, languages, and cultures, is a demanding task.

\section{WHAT DO HUMANS USE COMPUTING SYSTEMS FOR?}

Computing systems have become part of almost all the human activity. The following are key areas in which computing systems are used:

1. National defense and national security

2. The workplace

3. Education and training

4. Health care

5. Manufacturing

6. Research and development (R\&D) in science, engineering, and technology

\section{HOW DO HUMANS USE DATA AND INFORMATION?}

Humans use data and information to:

1. Understand and learn about the world from direct observation 
2. Understand and learn about the world from artifacts Create new information

3. Make decisions

4. Control processes

5. Communicate with other people

6. Communicate with computing systems

7. Share what they have learned and created with others

8. Explain, inform, and teach by deduction (the process of reasoning in which a conclusion follows necessarily from the stated premises). Humans have difficulty with deduction, using statistical results in consistent ways, and in using measures of uncertainty when making decisions. Humans validate their views of the world through experimentation, theory, and, more recently, computer-based modeling and simulation. Only humans can validate information resulting from these processes. [4][5]

Humans process information through their senses, by induction (deriving general principles from particular facts or instances), and

Table 1: Factors to be considered in the Design of Human Computer Interaction

\begin{tabular}{|c|c|c|c|c|}
\hline System Productivity & Human Performance & Training time and effectiveness & Cognitive Processes & Subjective satisfaction \\
\hline $\begin{array}{l}\text { 1. Applicability of } \\
\text { system to task } \\
\text { 2. Number of tasks } \\
\text { completed } \\
\text { 3. Quality of output }\end{array}$ & $\begin{array}{l}\text { 1. Speed of performance } \\
\text { 2. Rate and type of errors } \\
\text { 3. Quality of solutions to } \\
\text { problems }\end{array}$ & $\begin{array}{l}\text { 1. Time to learn how to use the } \\
\text { system } \\
\text { 2. Frequency of reference to } \\
\text { documentation } \\
\text { 3. Human retention of commands } \\
\text { over time }\end{array}$ & $\begin{array}{l}\text { 1. Appropriateness of } \\
\text { the mental model } \\
\text { 2. Degree of mental } \\
\text { effort }\end{array}$ & $\begin{array}{l}\text { 1. Satisfaction with self } \\
\text { 2. Satisfaction with } \\
\text { system } \\
\text { 3. Satisfaction with } \\
\text { performance }\end{array}$ \\
\hline
\end{tabular}

\section{HOW DO COMPUTING SYSTEMS USE DATA AND INFORMATION?}

The operations that a computer performs are specified by humans. The input to and the output from these operations are bits (sometimes organized into bytes) that have either been created digitally or converted from other forms. The input and output can be data or information, which a computer knows where to find because it is told the location explicitly (by a computer program that was created by humans). The tasks that computers can do better (meaning for example faster, more accurately, or at larger scale) than humans include:

1. Perform numerical calculations

2. Use mathematics to model and simulate real-world phenomena

3. Compare data sets and find statistical patterns

4. Use mathematical logic to reason deductively about information

5. Make decisions (based on rules established in computer processes set up by humans)

However, computers are currently less able than humans to:

1. Create information

2. Create new ways to communicate effectively with humans

3. Validate that their output is true

When humans allow computers to send instructions to actuators, those instructions can affect the real world. Computing systems need to demonstrate more stable and more reliable performance for humans to trust them to perform life critical operations. Even then, in order that informed decisions can be made, (1) humans will sometimes need to monitor and be able to override computer operations and (2) the computers will need to be programmed to provide information and interact with their human managers.

\section{CONCLUSION}

The subject of Human Computer Interaction is very rich both in terms of the disciplines it draws from as well as opportunities for research. Discussed here was just a small subset of the topics contained within HCI. The study of user interface provides a double-sided approach to understanding how humans and machines interact. In this paper, I have presented the interactivity of human computer interface where the human can interface with the machine.

\section{REFERENCES}

[1] Dr. Milind Oka, Management Information Systems: Text and Cases, Everest Publishing House, Pune, 2009.

[2] Efraim Turban, Jay E. Aronson (2003). Decision Support Systems and Intelligent Systems, $6^{\text {th }}$ edition. Pearson Education, New Delhi.

[3] Newell, A. and Simon, H.A., Human Problem Solving, Prentice-Hall, Englewood Cliffs, NJ, 1972.

[4] Rasmussen, J. Pejtersen, A., and Goodstein, L.G, Cognitive Systems Engineering, Wiley, New York, 1957.

[5] Simon, H.A., Models of Man, John Wiley \& Sons, New York, 1957.

[6] V.S. Janakiraman, K. Sarukesi, Decision Support Systems, Prentice Hall of India, New Delhi, 2002.

\section{AUTHORS BIOGRAPHY}

K P Tripathi received his M.C.A., degree from Shivaji University, Kolhapur in June 2006 and M.B.A. degree from YCMOU, Nashik in Feb. 2010. He is working as Assistant Professor in M.C.A. Department, Bharati Vidyapeeth Deemed University Institute of Management, Kolhapur, India. He has presented 6 papers in National Conferences and 5 papers in International Conferences. He has published 6 papers in International Journals and 1 in National Journal. He is member of IACSIT, ICEIT and CSI. His areas of interest include Information Technology, Computer Organization \& Architecture, and Mobile Communication. 